\title{
Revitalización de barrios patrimoniales en áreas metropolitanas: propuestas de monitoreo y gestión integradla
}

\author{
Revitalization of heritage neighborhoods in metropolitan areas: \\ proposals for monitoring and integrated management
}

\section{Resumen} tamara.jerisal@gmail.com

Recibido: 26/Sep/2021 Aceptado: 04/Dic/2021

*Universidad de Chile Tamara Jeri-Salgado"*

H. n Chile, la revitalización y puesta en valor de patrimonio urbano enfrenta desafíos de gobernanza urgentes y hace necesario el desarrollo de criterios de intervención adecuados. Para una conveniente gestión, se requiere coordinación entre procesos de protección, revitalización y desarrollo urbano, con metodologías de monitoreo que retroalimenten la toma de decisiones y fundamenten planes y proyectos patrimoniales apropiados a diferentes tipos de barrios patrimoniales. En este marco, proponemos un Índice de Evolución de Barrios Patrimoniales (IEBP), desarrollado en el marco de la investigación "Impacto de los instrumentos de protección patrimonial sobre la dinámica de barrios metropolitanos" (2019), que permite comparar procesos específicos en diferentes tipos de barrios. Se plantean conclusiones sobre la utilidad del IEBP para diferenciar dinámicas posteriores a la protección y proyectar políticas de revitalización que conjuguen la protección de los bienes culturales y el desarrollo urbano.

Palabras clave: evaluación; patrimonio; revitalización; barrios; urbanismo.

Abstract:

In Chile, the revitalization and enhancement of the urban heritage faces urgent governance $c$ enges and requires adequate intervention criteria. Heritage management demands greater coordination between processes of protection, revitalization and urban development, with monitoring methodologies that provide feedback for decision-making and support plans and heritage projects for different types of urban areas. In this framework, we propose an Index of Evolution of Heritage Neighborhoods developed by the research project "Impact of heritage protection instruments on the dynamics of metropolitan neighborhoods" (2019) that allows to compare specifics processes in different types of neighborhoods. Conclusions are raised about the utility of the IEHN to differentiate post-protection dynamics and project revitalization policies that combine the protection of cultural property and urban development.

Keywords: evaluation; heritage; revitalizing; neighborhood; urbanism. 


\section{Introducción}

En Chile se observa un escaso diálogo entre la planificación de las ciudades, la protección del patrimonio y el desarrollo urbano, lo que plantea el urgente desafío de formular planes más efectivos de puesta en valor de áreas patrimoniales urbanas locales, instrumentos que cuenten con mecanismos adecuados para evaluar sus resultados en el mediano y largo plazo.

Los principales instrumentos de gestión patrimonial existentes en el país son de tipo normativo. Las normativas de protección en áreas urbanas aplicadas en las ciudades, si bien han mitigado la pérdida de inmuebles de valor cultural, no han sido capaces de impulsar una gestión efectiva de su puesta en valor (Consejo Nacional de Desarrollo Urbano [CNDU], 2018). Por otra parte, desde la década de los noventa, el patrimonio urbano ha movilizado a diversas organizaciones ciudadanas, las cuales han buscado proteger áreas urbanas a través de Ley $\mathrm{N}^{\circ} 17.288$ de Monumentos Nacionales, por medio de la cual se declaran barrios como Zonas Típicas, evitando así la destrucción de su riqueza material e inmaterial. Cabe destacar que estas normas son diferentes de la protección que realizan los planes reguladores comunales o zonas de conservación histórica $(\mathrm{ZCH})$, que no son de gestión comunitaria sino de la tecnocracia municipal, y que se evitan o no son oportunos para promover proyectos de renovación e ingresos municipales por permisos.

En este marco, desde el Ejecutivo, a través de distintos ministerios, se han impulsado variadas iniciativas orientadas a la revitalización y puesta en valor del patrimonio urbano, en especial en aquellas áreas declaradas como Zonas Típicas. Tales acciones, sin embargo, se han desarrollado sin articulación entre sí; y aunque se detecta un número creciente de iniciativas ciudadanas que se suman al impulso de programas gubernamentales, no se ha logrado impedir el deterioro de muchas áreas urbanas. Ello ha ocurrido especialmente en las zonas metropolitanas, donde las acciones de revitalización patrimonial coexisten con dinámicas sociourbanas complejas que problematizan su implementación.

Lo anterior ocurre ya que, en la práctica, en Chile la función planificación existe y está formalizada, pero está desvalorizada, de hecho, por el propio Estado en su forma de organizar procesos de

${ }^{1}$ Las principales iniciativas programáticas impulsadas por el Ejecutivo son: Programa de Regeneración de Centros Históricos del Ministerio de Vivienda y Urbanismo (2018); Programa de Rehabilitación de Barrios e Infraestructura Patrimonial (PRBIPE), financiado por un contrato de préstamo del Banco Interamericano de Desarrollo y ejecutado por la Subsecretaría de Desarrollo Regional (2016); y Programa de Barrios Patrimoniales del Ministerio de Vivienda y Urbanismo (2014). inversión de corto plazo y supeditar el desarrollo de bienes públicos al interés del crecimiento económico inercial. Los Gobiernos Regionales, si bien definen imágenes de futuro y planes, en el día a día su función corresponde a la concursabilidad a escala de proyectos asistenciales; por su parte, los programas y proyectos son definidos a nivel sectorial, pero aplicados a nivel local (muy directamente determinados por lógicas sectoriales centrales y no por imágenes objetivo del desarrollo territorial). Este esquema explica lo que se hace y lo que se deja de hacer en zonas y áreas de significación o concentración patrimonial, pese a existir planes y protecciones, además de plantear la necesidad urgente de definir criterios de planificación integral de áreas urbanas con importante valor cultural (Arriagada, 2018). Asimismo, las políticas de protección y los programas de puesta en valor han abordado los barrios patrimoniales como entidades teóricamente homogéneas, con sesgos a la dimensión arquitectónica o de inmuebles, además, subestimando la existencia de distintas escalas, vocaciones, y en especial la existencia de grandes zonas patrimoniales localizadas en barrios centrales comerciales con gran atracción de población flotante, comercios informales y nodos de movilidad urbana que plantean necesidades de instrumentos y políticas ad hoc (por ejemplo, BID, 2019; Hernández, 2011; Bruquetas et al., 2005)

\subsection{La necesidad de realizar seguimiento y medir la evolución de barrios patrimoniales}

Los atributos deseados del desarrollo urbano en Chile deben ser traducidos a indicadores cuyo propósito sea medir brechas dentro y entre las ciudades del país (CNDU, 2017). La construcción de índices es una tendencia internacional (Programa de Naciones Unidas para el Desarrollo [PNUD], 2019), que permite sintetizar conceptos estratégicos bajo una medida resumen, siempre que esta cumpla exigencias estadísticas de intercorrelación y multicolinealidad y logre aclarar tendencias y estructuras ocultas del fenómeno analizado (Blalock,1986; Hernández Sampieri et al., 2006). En el ámbito urbano, varios organismos internacionales han diseñado índices sobre calidad de vida; entre ellos, el Banco Mundial, la Organización para la Cooperación y el Desarrollo Económicos (OCDE), el Banco Interamericano de Desarrollo (BID), y el Fondo de las Naciones Unidas para la Infancia (Unicef). En particular, son reconocidos el Índice de Bienestar Infantil de ciudades inglesas (Communities and Local Government. (2009); el Índice Calidad de Vida Urbana (MERCER, 2010 a 2019; Resonance Consultancy, 2020); los indicadores para auditoría urbana de 79 ciudades europeas (European Commission, 2013); y, en Chile, el Índice de Calidad de Vida Urbana (ICVU), elaborado por la Cámara Chilena de la Construcción y la Pontificia Universidad Católica de Chile (CCHC y PUC, 2019).

Cuando se realizó la investigación a partir de la cual se formula este artículo, en Chile no existía ninguna metodología de medición o indicadores para realizar seguimiento de la revitalización de barrios patrimoniales, pese a existir recomendaciones en este sentido provenientes de organismos como UNESCO y su lista de barrios reconocidos como Patrimonio de la Humanidad, 
Revitalización de barrios patrimoniales en áreas metropolitanas: propuestas de monitoreo y gestión integrada

y como el BID y su apoyo al Programa de Revitalización de Barrios e Infraestructura Patrimonial Emblemática en nuestro país (BID, s.f.).

\subsection{El barrio patrimonial como unidad de observación}

La valoración del barrio como unidad de observación en el ámbito del patrimonio tiene, entre otros referentes, a la Escuela Ecológica de Chicago, cuyos postulados definen la ciudad como un mosaico de áreas naturales menores cuya evolución es definida por patrones dinámicos de arreglo espacial entre grupos de población, usos e instituciones (Bassolls et al., 1988; Hall, 1996). Desde este enfoque, la interacción complementaria o conflictiva de los barrios con respecto a la dinámica dominante de sistema ecológico urbano, es interpretada de manera análoga a la vigente en el modelo biológico y ecológico.

En Latinoamérica, el estudio de los barrios patrimoniales ha sido abordado desde su heterogeneidad estructural inherente, vinculada a una historia social de la herencia cultural urbana signada como operación simbólica de un ideario de modernización e identidad hegemónico de las elites oligarcas, clases medias desarrollistas y, luego, de las empresas privadas. Fue esta misma visión la que, una vez que la región girara al neoliberalismo en el siglo $X X$, acentuó - entre otros efectos - el deterioro de patrimonio presente en barrios históricos centrales y populares (Carrión, 2001; García Canclini, 1989).

En la perspectiva anterior, el enfoque aplicado por este estudio destaca fundamentalmente la dimensión espacial del patrimonio y apuesta a hacer visible su escala territorial y comunitaria. Cabe recordar que, a lo largo de décadas, la protección de dichos bienes estuvo sesgada hacia el acervo arquitectónico y monumentos de culto o religioso, omitiendo en su quehacer e tejido que lo vincula a la comunidad y ciudad (Carrión, 2001). Ello a diferencia de las tendencias en Europa donde los programas de cohesión social advirtieron la trascendencia de la escala barrio, organizando en consecuencia proyectos para su regeneración, como, asimismo, de la importancia del componente desarrollo económico patrimonial y movilidad urbana (Bruquetas et al., 2005)

En Chile, el centralismo estatal, la debilidad de los instrumentos de planificación territorial y e economicismo, explican que la escala territorial de patrimonio urbano haya sido opaca frente a procesos de renovación urbana depredadores, mercantilizantes o distorsionadores de este acervo cultural, favoreciendo su aislamiento y mutación a "no lugares" (Arriagada, 2013).

Por su parte, el esquema de protección del patrimonio arquitectónico aplicado tanto por la agencia estata competente en esta materia (Consejo de Monumentos Nacionales), como por el marco legal que regula todo lo atingente a las edificaciones (Ordenanza de Urbanismo y Construcción), han privilegiado la escala inmueble y el monumento, sin visión multi-escalar ni integralidad. Con ello, las áreas urbanas patrimoniales han sido concebidas como un conjunto de piezas patrimoniales individuales en un territorio dado. Sin embargo, para las comunidades que han impulsado la protección de estas zonas urbanas de valor patrimonial, tan importantes como el patrimonio inmueble que en ellas se aloja son sus aspectos inmateriales; entre ellos, los estilos de vida desarrollados en dichos territorios, y su tejido social o sistema vinculado a la identidad de la comunidad. En este estudio se ha hecho, por lo mismo, un esfuerzo de estudio desagregado de dos bloques o tipos de barrios patrimoniales, unos de vocación residencial y otros hoy marcados por la mixtura de usos y procesos económicos, urbanos de gran envergadura.

En vista de las tendencias señaladas, y para contribuir a la implementación de sistemas integrados de gestión de barrios patrimoniales en áreas urbanas, se desarrolló el proyecto de investigación "Impacto de los instrumentos de protección patrimonial sobre la dinámica de barrios metropolitanos" (Arriagada y Berg, 2019), con e patrocinio de la Facultad de Arquitectura de la Universidad de Chile y el financiamiento del Fondo Nacional de la Cultura y las Artes. La investigación se abocó a observar diez barrios patrimoniales como sistemas donde interactúan dimensiones físicas y dimensiones sociales y que, a su vez, reflejan procesos de interacción de territorio y su entorno a lo largo del tiempo, siendo uno de sus resultados, la producción de una metodología de monitoreo de revitalización de barrios patrimoniales. Este artículo muestra los resultados de dicha investigación ${ }^{2}$ y su propuesta de metodología para realizar el seguimiento y producir información que permita orientar la toma de decisiones en un modelo de gestión urbana integrada en esta escala.

De tal modo, se analizan aquí los datos segmentados por tipos de barrios que reconocen un conjunto de evidencias que permiten responder la interrogante acerca de cómo han evolucionado los barrios patrimoniales insertos en áreas metropolitanas en Chile desde que se han aplicado instrumentos normativos de protección, considerando sus dimensiones físicas y sociales, y gruesamente dos dinámicas específicas de comportamiento, según se trate de barrios mixtos o residenciales, donde tendencias y desafíos de gestión se bifurcan.

A continuación, se desarrolla la metodología de formulación del IEBP y las dimensiones y variables que la componen. Luego se presentan los resultados de la aplicación del Índice en diez barrios patrimoniales localizados en ciudades metropolitanas, destacándose las principales tendencias de evolución de estas zonas urbanas. En la sección de cierre se presentan conclusiones metodológicas sobre la utilidad del Índice y sus factores por tipos de barrios patrimoniales, así como respecto de su uso para proyectar políticas de revitalización urbana que conjuguen la protección del patrimonio y el desarrollo urbano.

${ }^{2}$ En dicho proyecto (2018-2019), participaron C. Arriagada y L. Ber como investigadores principales, y T. Jeri, P. Acuy e I. Alt como coinvestigadoras. 


\section{Métodos}

\subsection{Muestra y fuentes consultadas}

Se observaron 10 barrios patrimoniales en cuatro regiones del país, que corresponden a áreas urbanas protegidas mediante declaratorias de Zonas Típicas por la Ley de Monumentos Nacionales, o bien como Zonas de Conservación Histórica en la regulación de cada comuna. La selección de estos barrios consideró los siguientes criterios: pertenencia de las comunas a Áreas Metropolitanas Mayores y emergentes, localizadas al norte y sur del país, considerando municipios donde hubiese concentración de protecciones patrimoniales relevantes, tanto de escala predial como barrial o zonal, y además existiesen viviendas tipo conventillo o cité. Se seleccionaron casos de barrios de vocación y uso de facto residencial (4) y zonas de uso mixto, marcadas por la presencia relevante de usos comerciales formales e informales, gran flujo de población flotante y movilidad urbana.

Globalmente, los territorios están habitados por 47.700 habitantes y 18.277 hogares, según el Censo de Población 2017 (Instituto Nacional de Estadísticas [INE], 2017), en una superficie de 689 hectáreas, donde se concentra un tercio de los Inmuebles de Conservación Histórica y casi tres cuartos del total de zonas típicas del país. La Tabla 1 cuantifica el tamaño espacial y demográfico de los 10 barrios, y la región a la cual pertenece.

En cuanto a las fuentes empleadas, se contempló: i) Encuesta a residentes y locatarios comerciales con una muestra lograda de 390 casos, con un error $+/-3,5 \%$ por región (considerando cuatro regiones), +/- 2,8\% por tipo de entrevistado a nivel nacional (residente o locatario), con un $95 \%$ de confianza. A escala de barrios, los niveles de error oscilan entre $6 \%$ y $10 \%$, y son reportados con fines ilustrativas de las tendencias detectadas por segmentos barriales. La encuesta es la fuente para la estimación del Índice de Evolución de Barrios Patrimoniales.

ii) Observación del territorio y generación de cartografías con localización de inmuebles de valor patrimonial, así como de equipamiento, espacios públicos e infraestructura, cualificando su calidad en términos de su aporte a la revitalización del barrio, como elementos atractores o deteriorantes. La observación complementa la aplicación del índice, aportando elementos interpretativos al análisis.

iii) Procesamiento de estadísticas oficiales: Censo de Población 2017, datos policiales de la Subsecretaría de Prevención del Delito, datos de valor fiscal de los predios según el Servicio de Impuestos Internos, datos municipales del Sistema Nacional de Información Municipal, e indicadores del Sistema de Indicadores y Estándares de Desarrollo Urbano que administra e Instituto Nacional de Estadísticas. El procesamiento de estas fuentes secundarias tiene por finalidad comprender el contexto de evolución de barrios patrimoniales y aislar factores externos en la interpretación de los datos.

\begin{tabular}{|c|c|c|c|c|c|}
\hline Región & $\begin{array}{l}\text { Barrios patrimo- } \\
\text { niales }\end{array}$ & $\begin{array}{l}\text { Tipo de } \\
\text { barrio }\end{array}$ & $\begin{array}{l}\text { Superficie } \\
\text { (hectáreas) }\end{array}$ & $\begin{array}{c}\text { Promedio de } \\
\text { hogares por } \\
\text { manzana }\end{array}$ & $\begin{array}{l}\text { Promedio de } \\
\text { habitantes por } \\
\text { manzana }\end{array}$ \\
\hline \multirow{2}{*}{$\begin{array}{l}\text { Región de Co- } \\
\text { quimbo }\end{array}$} & $\begin{array}{l}\text { 1. Centro histórico, } \\
\text { La Serena }\end{array}$ & Mixto & 170 & 20 & 62 \\
\hline & $\begin{array}{l}\text { 2. Guayacán, Co- } \\
\text { quimbo }\end{array}$ & Residencial & 96 & 16 & 53 \\
\hline \multirow{3}{*}{$\begin{array}{l}\text { Región de Valpa- } \\
\text { raíso }\end{array}$} & $\begin{array}{l}\text { 3. Área Calle Liber- } \\
\text { tad, Viña del Mar }\end{array}$ & Mixto & 7 & 56 & 130 \\
\hline & $\begin{array}{l}\text { 4.Almendral, Val- } \\
\text { paraíso }\end{array}$ & Mixto & 146 & 44 & 108 \\
\hline & $\begin{array}{l}\text { 5. La Matriz, Val- } \\
\text { paraíso }\end{array}$ & Residencial & 3 & 10 & 24 \\
\hline \multirow{4}{*}{$\begin{array}{l}\text { Región Metropo- } \\
\text { litana de Santiago }\end{array}$} & $\begin{array}{l}\text { 6. Huemul, San- } \\
\text { tiago }\end{array}$ & Residencial & 8 & 63 & 165 \\
\hline & $\begin{array}{l}\text { 7. Los Castaños, } \\
\text { Independencia }\end{array}$ & Residencial & 4 & 66 & 187 \\
\hline & $\begin{array}{l}\text { 8. Mapocho, Inde- } \\
\text { pendencia }\end{array}$ & Mixto & 120 & 118 & 319 \\
\hline & 9. Yungay, Santiago & Mixto & 114 & 65 & 163 \\
\hline $\begin{array}{l}\text { Región de Los } \\
\text { Lagos }\end{array}$ & $\begin{array}{l}\text { 10. Centro históri- } \\
\text { co, Puerto Varas }\end{array}$ & Mixto & 21 & 24 & 78 \\
\hline
\end{tabular}

Tabla 1: Datos sociodemográficos de barrios patrimoniales analizados, a partir de los cuales se construye y mide el Índice de Evolución de Barrios Patrimoniales 
Revitalización de barrios patrimoniales en áreas metropolitanas: propuestas de monitoreo y gestión integrada

\subsection{Construcción de Índice de Evolución de Barrios Patrimoniales}

Para dar cuenta de tendencias en la evolución de los barrios patrimoniales considerados en el estudio, se construyó a partir de la encuesta una medida resumen que entrega un orden de magnitud sobre fenómenos sociales, de un conjunto de parámetros o atributos diversos. A esta medida resumen se la denominó Índice de Evolución de Barrios Patrimoniales (IEBP). Este Índice arroja valores de 0 a 100, que reflejan una gradiente desde el deterioro hasta la revitalización, y conjuga información de la evolución de cuatro ámbitos: i) vivienda $e$ inmuebles, ii) entorno urbano, iii) economía patrimonial, y iv) capital social patrimonial. En cada uno de estos ámbitos se recogen medidas de tendencia y cambios en dotación, calidad y uso. Esto permite dar cuenta de regiones, donde se consultó su opinión sobre cuáles eran los indicadores fundamentales de monitoreo e imagen objetivo de la revitalización.

El índice se compone de 12 variables, medidas a través de 12 indicadores en los cuatro ámbitos que se construyen mediante procedimientos de integración de preguntas de la encuesta (Tabla 2)

El IEBP combina cuatro subíndices, que corresponden a los cuatro ámbitos, cuya medida resumen oscila en un rango teórico desde valor 0 (cuando la evolución de barrio expresa deterioro barrial), hasta el valor máximo de 100 (cuando existe una evolución positiva en los cuatro factores del sistema patrimonial), pasando por rangos intermedios indicativos de situaciones donde un grupo de variables mejora, en paralelo a otro que revela

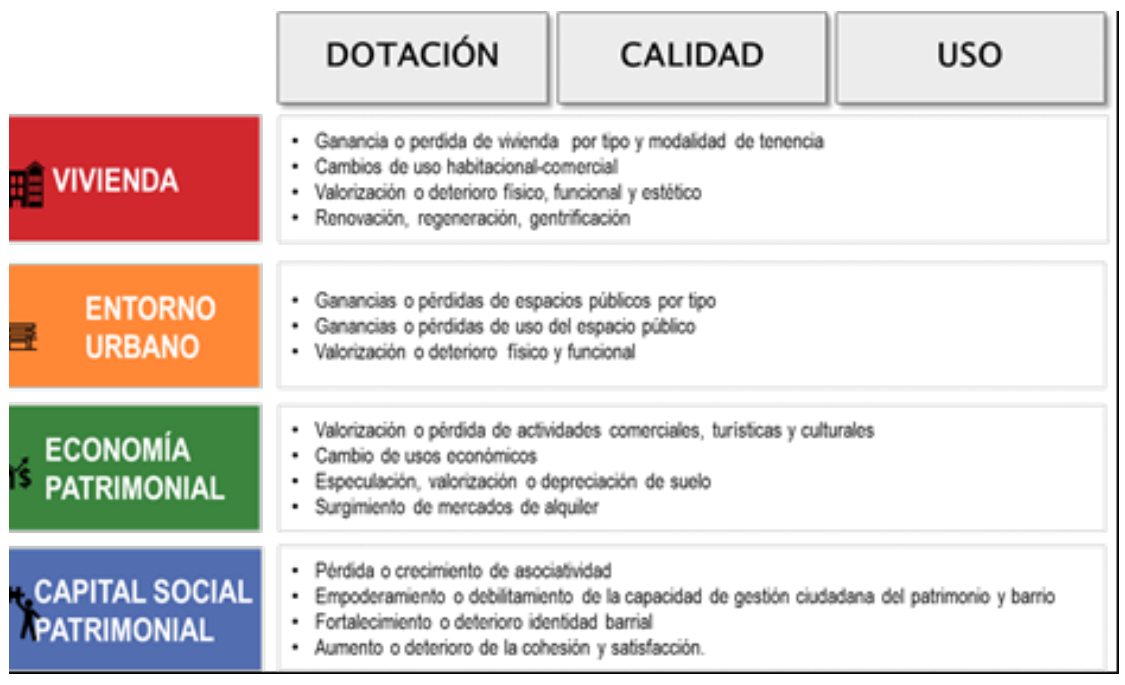

Figura 1: Ámbitos y atributos que se recogen en el IEBP

Fuente: Propuesta formulada en Investigación Arriagada y Berg, 2019

diferentes tendencias valorizantes o deteriorantes que pueden ocurrir en los distintos ámbitos. Las principales tendencias que recoge el índice se expresan en la Figura 1. La determinación de estos cuatro ámbitos y de los atributos posibles de observar fue realizada a partir de la revisión de las propuestas del Consejo Nacional de Desarrollo Urbano en relación con el patrimonio (CNDU, 2018) y de los postulados de la Política Nacional de Desarrollo Urbano en el eje de Identidad y Patrimonio (CNDU, 2014). Asimismo, se atendieron los componentes propuestos para planes de revitalización y regeneración de barrios patrimoniales de la versión 2013 del Programa de Recuperación de Barrios en su modalidad patrimonial, del Ministerio de Vivienda y Urbanismo, así como de Programa de Revitalización de Barrios e Infraestructura patrimonial (PRBIPE), iniciativa patrocinada por el BID y la Subsecretaría de Desarrollo Regional y Administrativo del Gobierno de Chile (SUBDERE). Por último, se realizaron dos talleres con 16 especialistas en urbanismo y patrimonio, a quienes se consultó por los atributos de barrios patrimoniales que debieran ser monitoreados; a ellos se sumaron cerca de 100 entrevistas a profesionales sectoriales, municipales y dirigentes vecinales de cuatro deterioro o estancamiento (situación frecuente donde la clave es poder entender avances y retrocesos al tenor de los efectos de protecciones y/o intervenciones más o menos eficaces). Cabe reiterar que, en general, en Chile no existen evaluaciones similares, sino estudios de casos únicos como tendencia general centrados en las dimensiones arquitectónica y solo recientemente ha habido un auge o atención al patrimonio intangible y las oportunidades de gestión cultural asociadas a estas zonas.

La construcción de estos subíndices corresponde a la suma ponderada de los indicadores correspondientes (Tabla 3). Bajo la misma metodología, el valor final del IEPB resulta de la suma ponderada de los 4 subíndices. La ponderación se definió a partir de consulta a expertos en patrimonio y urbanismo. 


\begin{tabular}{|c|c|c|c|}
\hline Ámbito & Variables & Indicadores & Constructo indicador \\
\hline \multirow{3}{*}{ Vivienda } & $\begin{array}{l}\text { V.1 Estado de conservación } \\
\text { de inmuebles residenciales }\end{array}$ & $\begin{array}{l}\text { Cambio en estado de conservación (mejor/ } \\
\text { peor) de vivienda ocupada y viviendas del } \\
\text { entorno. }\end{array}$ & $\begin{array}{l}\text { Integración: Suma puntaje de } 2 \\
\text { preguntas Likert y normalización de } \\
0 \text { a } 100 \text { donde } 0 \text { es mucho peor y } 100 \\
\text { mucho mejor } \\
\text { Lectura: Ascendente } \\
\text { Escala: } 0-100 \text { (continua) }\end{array}$ \\
\hline & $\begin{array}{l}\text { V.2 Estado de conservación } \\
\text { del patrimonio físico }\end{array}$ & $\begin{array}{l}\text { Estado de conservación de cuatro tipos de } \\
\text { inmuebles (inmuebles históricos, monu- } \\
\text { mentos, inmuebles religiosos, inmuebles } \\
\text { institucionales) y dos tipos de espacios } \\
\text { patrimoniales del barrio (calles y elementos } \\
\text { decorativos en espacio público) }\end{array}$ & $\begin{array}{l}\text { Integración: Suma puntaje de } 6 \text { pregun- } \\
\text { tas Likert y normalización de } 0 \text { a } 100 \\
\text { donde } 0 \text { es muy mal conservado y } 100 \\
\text { muy bien conservado } \\
\text { Lectura: Ascendente } \\
\text { Escala: } 0-100 \text { (continua) }\end{array}$ \\
\hline & $\begin{array}{l}\text { V.3 Ausencia de inmuebles } \\
\text { deteriorantes }\end{array}$ & $\begin{array}{l}\text { Ausencia de cinco inmuebles con usos y con- } \\
\text { diciones deteriorantes (casas desocupadas, } \\
\text { inmuebles en condiciones precarias o mar- } \\
\text { ginales, ocupados como bodega, ocupación } \\
\text { irregular, riesgos de derrumbe). }\end{array}$ & $\begin{array}{l}\text { Integración: Suma puntaje de } 5 \text { pregun- } \\
\text { tas Likert y normalización de } 0 \text { a } 100 \\
\text { donde } 0 \text { es presencia abundante y } 100 \\
\text { ausencia } \\
\text { Lectura: Ascendente } \\
\text { Escala: } 0-100 \text { (continua) }\end{array}$ \\
\hline \multirow{3}{*}{ Entorno urbano } & $\begin{array}{l}\text { EU.1 Calidad bienes públi- } \\
\text { cos urbanos }\end{array}$ & $\begin{array}{l}\text { Estado de conservación percibido de nueve } \\
\text { bienes públicos urbanos: plazas y parques, } \\
\text { canchas y multicanchas, veredas, calles y } \\
\text { pasajes, iluminación, paraderos, basureros y } \\
\text { bancas, juegos infantiles. }\end{array}$ & $\begin{array}{l}\text { Integración: Promedio puntaje de } 9 \\
\text { preguntas Likert y normalización de } 0 \text { a } \\
100 \text { donde } 0 \text { es muy mal conservados y } \\
100 \text { muy bien conservado } \\
\text { Lectura: Ascendente } \\
\text { Escala: } 0-100 \text { (continua) }\end{array}$ \\
\hline & $\begin{array}{l}\text { EU.2 Evolución de equipa- } \\
\text { miento de espacio público }\end{array}$ & $\begin{array}{l}\text { Percepción de evolución de nueve bienes } \\
\text { públicos urbanos respecto de antes de } \\
\text { protección patrimonial del barrio: plazas y } \\
\text { parques, canchas y multicanchas, veredas, } \\
\text { calles y pasajes, iluminación, paraderos, } \\
\text { basureros y bancas, juegos infantiles. }\end{array}$ & $\begin{array}{l}\text { Integración: Suma de puntaje de } 9 \\
\text { preguntas Likert normalizadas de } 0 \text { a } \\
100 \text { donde } 0 \text { es están mucho peor que } \\
\text { antes y } 100 \text { mucho mejor que antes } \\
\text { Lectura: Ascendente } \\
\text { Escala: } 0-100 \text { (continua) }\end{array}$ \\
\hline & $\begin{array}{l}\text { EU.3 Ausencia de activi- } \\
\text { dades deteriorantes en el } \\
\text { espacio público }\end{array}$ & $\begin{array}{l}\text { Ausencia de actividades deteriorantes en } \\
\text { el espacio público: comercio ambulante, } \\
\text { vagancia, consumo y venta drogas y alcohol, } \\
\text { microbasurales, perros vagos, rayado de } \\
\text { muros. }\end{array}$ & $\begin{array}{l}\text { Integración: Suma de puntaje de } 6 \\
\text { preguntas Likert normalizadas de } 0 \text { a } \\
100 \text { donde } 0 \text { es ausencia en el espacio } \\
\text { público del barrio y } 100 \text { presencia } \\
\text { frecuente } \\
\text { Lectura: Ascendente } \\
\text { Escala: } 0 \text {-100 (continua) }\end{array}$ \\
\hline \multirow{4}{*}{$\begin{array}{l}\text { Economía } \\
\text { patrimonial }\end{array}$} & $\begin{array}{l}\text { EP.1 Incremento de activi- } \\
\text { dad comercial formal }\end{array}$ & $\begin{array}{l}\text { Percepción de incremento de tres actividades } \\
\text { comerciales: 'locales comerciales' y 'restau- } \\
\text { rantes y cafeterías de buen nivel', y existencia } \\
\text { en buenas condiciones de 'comercio de cosas } \\
\text { y servicios típicos'. }\end{array}$ & $\begin{array}{l}\text { Integración: Suma de puntaje de } 3 \\
\text { preguntas Likert normalizadas de } 0 \text { a } \\
100 \text { donde } 0 \text { es reducción de actividad } \\
\text { comercial y } 100 \text { incremento } \\
\text { Lectura: Ascendente } \\
\text { Escala: } 0-100 \text { (continua) }\end{array}$ \\
\hline & $\begin{array}{l}\text { EP.2 Alza de precios de } \\
\text { inmuebles sin expulsión }\end{array}$ & $\begin{array}{l}\text { Percepción de alza en precio de valorización } \\
\text { de inmuebles, mejor estado de los mismos, } \\
\text { sin que ello implique expulsión de familias de } \\
\text { menores ingresos y concomitante llegada de } \\
\text { personas de mayores ingresos. }\end{array}$ & $\begin{array}{l}\text { Integración: Cualitativa, a partir de } \\
\text { la combinatoria de respuesta en tres } \\
\text { preguntas. } \\
\text { Valor final en escala } 0 \text { a } 100 \text { donde } 0 \\
\text { reducción de precios y tugurización o } \\
\text { alza de precios y expulsión y } 100 \text { incre- } \\
\text { mento de valor y retención de familias } \\
\text { Lectura: Ascendente } \\
\text { Escala: } 0-100 \text { (discontinua) }\end{array}$ \\
\hline & $\begin{array}{l}\text { EP.3 Contención de activi- } \\
\text { dad económica inmobiliaria } \\
\text { perjudicial }\end{array}$ & $\begin{array}{l}\text { Percepción de no incremento de actividad } \\
\text { comercial inmobiliaria perjudicial para patri- } \\
\text { monio (construcción de edificios en altura, } \\
\text { venta de casas o departamentos antiguos). }\end{array}$ & $\begin{array}{l}\text { Integración: Suma de puntaje de } 2 \\
\text { preguntas Likert normalizadas de } 0 \text { a } \\
100 \text { donde } 0 \text { es aumento de actividad } \\
\text { inmobiliaria y } 100 \text { no incremento } \\
\text { Lectura: Ascendente } \\
\text { Escala: } 0-100 \text { (continua) }\end{array}$ \\
\hline & $\begin{array}{l}\text { EP.4 Dinamización del } \\
\text { mercado de alquiler }\end{array}$ & $\begin{array}{l}\text { Percepción de incremento de la actividad } \\
\text { inmobiliaria de alquiler y de atracción de } \\
\text { inmigrantes internacionales, familias con } \\
\text { hijos y/o jóvenes. }\end{array}$ & $\begin{array}{l}\text { Integración: Cualitativa, a partir de } \\
\text { la combinatoria de respuesta en } 4 \\
\text { preguntas. } \\
\text { Valor final en escala } 0 \text { a } 100 \text { donde } 0 \text { no } \\
\text { dinamización de mercado de alquiler } \\
\text { o aumento de alquiler precario y } 100 \\
\text { dinamización favorable de mercado de } \\
\text { alquiler } \\
\text { Lectura: Ascendente } \\
\text { Escala: } 0-100 \text { (discontinua) }\end{array}$ \\
\hline
\end{tabular}


Revitalización de barrios patrimoniales en áreas metropolitanas: propuestas de monitoreo y gestión integrada

\begin{tabular}{|c|c|c|c|}
\hline \multirow{2}{*}{$\begin{array}{l}\text { Capital social } \\
\text { patrimonial }\end{array}$} & $\begin{array}{l}\text { CS.1 Conocimiento del } \\
\text { patrimonio }\end{array}$ & $\begin{array}{l}\text { Grado de conocimiento de aspectos } \\
\text { patrimoniales del barrio: historia del barrio, } \\
\text { arquitectura y monumentos o edificios de } \\
\text { interés patrimonial. }\end{array}$ & $\begin{array}{l}\text { Integración: Suma de puntaje de } 3 \\
\text { preguntas Likert normalizadas de } 0 \text { a } \\
100 \text { donde } 0 \text { es desconocimiento de } \\
\text { aspectos patrimoniales y } 100 \text { conoci- } \\
\text { miento elevado de todos } \\
\text { Lectura: Ascendente } \\
\text { Escala: } 0-100 \text { (continua) }\end{array}$ \\
\hline & $\begin{array}{l}\text { CS.2 Gestión social del } \\
\text { patrimonio }\end{array}$ & $\begin{array}{l}\text { Frecuencia de realización de 'proyectos que } \\
\text { promueven y difunden el patrimonio y la } \\
\text { cultura'. }\end{array}$ & $\begin{array}{l}\text { Normalización de } 1 \text { pregunta de escala } \\
1 \text { a } 15 \text { a otra de } 0 \text { a } 100 \text { donde } 0 \text { es la } \\
\text { no realización de actividades de promo- } \\
\text { ción del patrimonio y cultura y } 100 \text { la } \\
\text { realización frecuente } \\
\text { Lectura: Ascendente } \\
\text { Escala: } 0-100 \text { (discontinua) }\end{array}$ \\
\hline
\end{tabular}

Tabla 2: Variables e indicadores del Índice de Evolución de Barrios Patrimoniales

Fuente: Elaboración propia

\begin{tabular}{|l|l|c|c|}
\hline \multicolumn{1}{|c}{ ÍNDICE } & \multicolumn{1}{c|}{ Subíndices } & Ponderación & Rango del índice \\
\hline \multirow{3}{*}{$\begin{array}{l}\text { Índice de Evolución de } \\
\text { Barrios Patrimoniales }\end{array}$} & Vivienda & $22,5 \%$ & \\
\cline { 2 - 3 } & Entorno Urbano & $28,8 \%$ & \multirow{2}{*}{$0-100$} \\
\cline { 2 - 3 } & Economía patrimonial & $16,3 \%$ & \\
\cline { 2 - 3 } & Capital social & $32,5 \%$ & \\
\hline
\end{tabular}

Tabla 3: Ponderación de Subíndices por Componentes patrimoniales para construcción de IEBP Fuente: Elaboración propia en base a consulta a expertos

Se realiza un análisis estratificado comparando tendencias entre los barrios agrupados según dos modalidades: barrios de uso mixto $(1,3,4,8,9$ y 10 según Tabla 1); y barrios patrimoniales residenciales (2,
5, 6 y 7), cuyas características se resumen en la Figura 2 y reportan diferencias de tendencias y rol de los factores o componentes que son de relevancia sustantiva para gestión y proyectos adecuados.
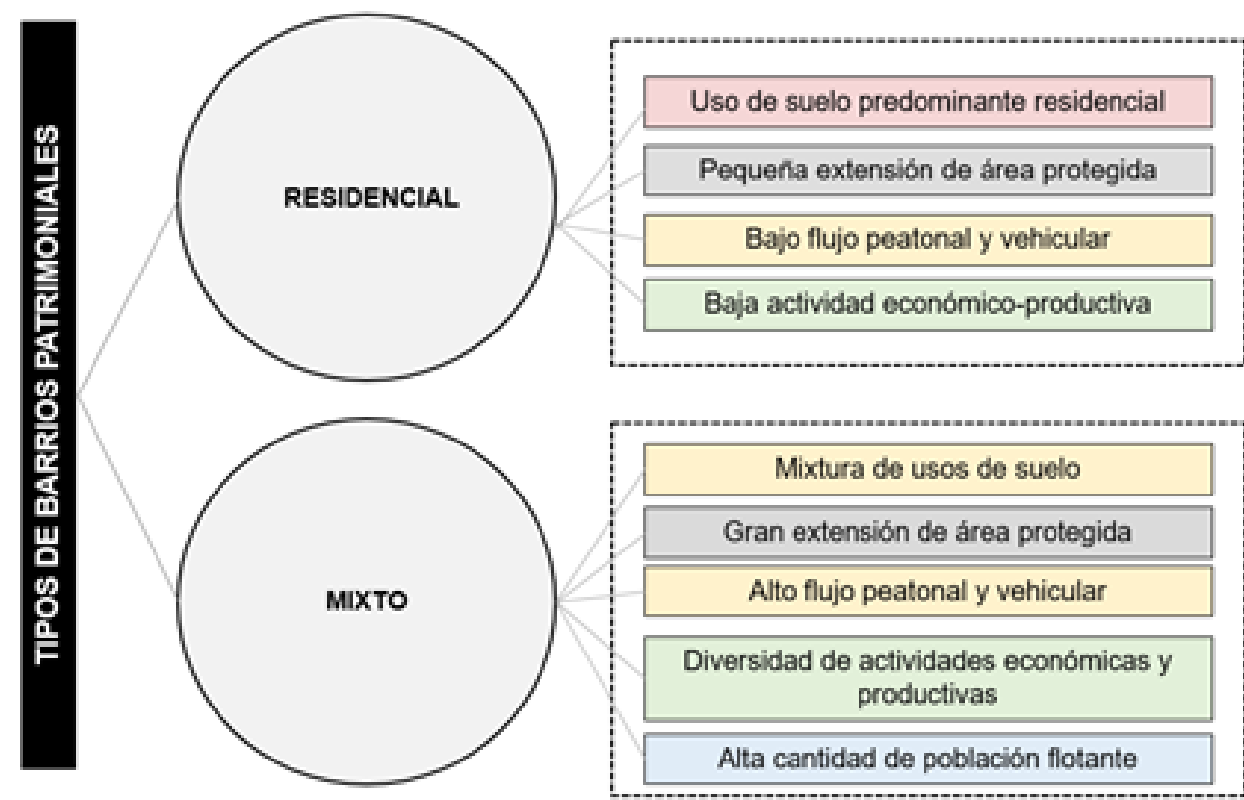

Figura 2: Tipos de barrios patrimoniales

Fuente: Berg et al. (2019) 


\section{Resultados de la aplicación del IEBP}

\subsection{Tendencias sociodemográficas en los barrios patrimoniales en áreas metropolitanas}

A partir del análisis intercensal de los barrios patrimoniales (entre los años 2002 y 2017), es posible evidenciar algunas tendencias significativas comparando la situación anterior y posterior a su protección.

En cuanto al crecimiento poblacional, las tasas de crecimiento anual en las zonas patrimoniales observadas son bastante superiores a la tasa de crecimiento intercensal a nivel país (1\% anual entre 2002 y 2017), lo que muestra que la protección del patrimonio no va asociada a un despoblamiento generalizado de los barrios como destaca la literatura de larga data hasta inicios de los años noventa. El dinamismo demográfico ha sido mayor en zonas de uso mixto, con presencia de uso comercial y población flotante, debido a su mayor superficie, cabida y conectividad, destacando Puerto Varas (37\%), Yungay y Mapocho (8,3\%), y también
Viña del Mar (4,6\%), mientras que otras áreas están estancadas (La Matriz, Guayacán, Almendral y La Serena).

Pese a que la población en zonas protegidas crece, el estancamiento del parque de viviendas es notable: en total, en los barrios donde se aplicó el estudio habitan 18 mil hogares en solo 3 mil viviendas, lo que da un déficit habitacional superior a 15 mil unidades. Los casos extremos son Yungay, Almendral, Mapocho y el centro histórico de La Serena, esto supone todos los casos de barrios mixtos donde se densificó el parque existente sin que se localizaran viviendas económicas, a la par de verificarse un incremento de vivienda desocupada entre 2002 y 2017.

De acuerdo con la estructura de edades, se observa, por un lado, una fuerte reducción de personas mayores en tres barrios de tipo mixtos (Mapocho, Puerto Varas y Yungay), con el consiguiente recambio por poblaciones más jóvenes, mientras que otros barrios patrimoniales, del tipo residencial, muestran una mayor tendencia a envejecimiento. Destacan al respecto La Matriz, donde la tasa de envejecimiento se multiplicó por diez entre 2002 y 2017, situación similar a la de Guayacán, todas estas zonas estancadas en su crecimiento de población (Tabla 4).

\begin{tabular}{|c|c|c|c|c|c|c|c|}
\hline & $\begin{array}{l}\text { Tasa prome- } \\
\text { dio anual de } \\
\text { crecimiento } \\
\text { por cada } 100 \\
\text { habitantes }\end{array}$ & $\begin{array}{l}\text { Variación } \\
\text { de hogares } \\
\text { en zona } \\
\text { patrimonial } \\
(\%)\end{array}$ & $\begin{array}{l}\text { Variación } \\
\text { de hogares } \\
\text { unipersona- } \\
\text { les respecto } \\
\text { del total de } \\
\text { hogares (\%) }\end{array}$ & $\begin{array}{l}\text { Variación de } \\
\text { la tasa de } \\
\text { extranjeros } \\
\text { por } 1000 \\
\text { personas } \\
\text { nacionales } \\
\text { en zona } \\
\text { patrimonial } \\
(\%)\end{array}$ & $\begin{array}{l}\text { Variación de } \\
\text { tasa de en- } \\
\text { vejecimien- } \\
\text { to en zona } \\
\text { patrimonial } \\
(\%)\end{array}$ & $\begin{array}{l}\text { Variación de } \\
\text { población } \\
\text { adulta con } \\
\text { estudios } \\
\text { superiores } \\
(\%)\end{array}$ & $\begin{array}{l}\text { Variación de } \\
\text { viviendas de } \\
\text { uso residen- } \\
\text { cial (\%) }\end{array}$ \\
\hline Valor país & 1,0 & 36,4 & 53,45 & 242 & 81,52 & 36 & 0 \\
\hline $\begin{array}{l}\text { Conjunto } \\
\text { Barrios pa- } \\
\text { trimoniales }\end{array}$ & 34,8 & 506 & 28 & 380 & 11 & 25 & 0 \\
\hline Barrio Mixto & 38,2 & 558 & 25 & 353 & 1 & 24 & 0 \\
\hline $\begin{array}{l}\text { Barrio Resi- } \\
\text { dencial }\end{array}$ & 18,2 & 222 & 47 & 478 & 84 & 27 & -5 \\
\hline $\begin{array}{l}\text { Centro La } \\
\text { Serena }\end{array}$ & 15,0 & 146,9 & 56,0 & 264,9 & 261,8 & 20.8 & 0 \\
\hline Guayacán & 13,5 & 135,2 & 82,8 & $-35,4$ & 163,8 & 44.1 & 0 \\
\hline La Matriz & 12,0 & 138,0 & 14,7 & $-65,1$ & 566,7 & 52.5 & -0.2 \\
\hline Almendral & 22,5 & 301,1 & 58,8 & 246,6 & 62,7 & 42.5 & 0 \\
\hline Almendral & 46,1 & 831,0 & 52,0 & $-64,4$ & 120,7 & 20.0 & -0.10 \\
\hline Huemul & 19,6 & 232,7 & 15,5 & 992,0 & 22,0 & 51.7 & -0.90 \\
\hline Los Castaños & 24,7 & 346,1 & 61,1 & 477,7 & 37,3 & -6.9 & 1.80 \\
\hline Mapocho & 83,7 & 1337,4 & 20,6 & 278,8 & $-57,8$ & 64.7 & -0.60 \\
\hline Yungay & 83,7 & 1203,5 & 9,1 & 108,3 & $-3,6$ & 12.6 & -1.70 \\
\hline Puerto Varas & 369,8 & 4942,9 & 64,5 & $-15,9$ & $-52,2$ & 52.8 & 0 \\
\hline
\end{tabular}

Tabla 4: Variación de indicadores sociodemográficos intercensos (2002-2017)

Fuente: Elaboración propia con base en datos del Censo de Población 2002 y 2017 para las manzanas censales de los 10 barrios patrimoniales 
Revitalización de barrios patrimoniales en áreas metropolitanas: propuestas de monitoreo y gestión integrada

Respecto de las condiciones de vulnerabilidad social de la población residente, es llamativo advertir que existen algunas tendencias comunes a barrios mixtos $y$ residenciales. Entre estas destaca el alza en la población económicamente activa (PEA), de un $26 \%$ entre 2002 y 2017 , duplicando el alza a nivel nacional $(13,6 \%)$, lo que podría explicarse por la atracción de población migrante internacional, compuesta predominantemente de trabajadores o personas en busca de trabajo en zonas centrales. Los barrios con mayor alza en este sentido son Mapocho (mixto) y Los Castaños (residencial) pero tambien Huemul, residencial pero adyacente al barrio Franklin, comercial, que parece invadirlo, los cuales, coincidentemente, son los que también incrementaron sus tasas de población migrante por 1000 habitantes. Asimismo, se observa que, en su mayoría, los barrios patrimoniales están sub-representados en la atracción o crecimiento de población residente calificada (con estudios superiores), lo que contraviene los conceptos de gentrificación cultural asociados en la literatura a barrios de valor patrimonial. En los 10 barrios, si bien entre los censos 2002 y 2017 se produjo un incremento del 25\% de personas con calificación, tal cifra está por debajo de incremento nacional (36\%). Por otra parte, en algunos de estos barrios se produce una clara expulsión de personas calificadas (Los Castaños, mixto). Sin embargo, existen casos de barrios mixtos de atracción de población calificada (Mapocho, Centro Histórico de Puerto Varas, y Almendral), cuyas alzas convergen a la variación nacional, y corresponden a barrios que se localizan donde han existido enclaves de remodelación de inmuebles para arriendo de profesionales y estudiantes, y se posicionan mejores atractivos culturales y comerciales.

\subsection{Aplicación del IEBP}

A nivel global, el IEBP arroja como resultado que, en los 10 barrios estudiados, se aprecia un nivel moderado de revitalización. Sin embargo, existen diferencias estadísticamente significativas por tipología del barrio, siendo mayor el grado de revitalización en los barrios de uso mixto que en los residenciales. Estas tendencias están correlacionadas con diferencias de escala entre los barrios y el efecto diferencial en el índice de los factores o componentes por tipo de barrio, que determinan que existan claves específicas de deterioro en unos $y$ claves de revitalización parciales en otros (Figura 3). En efecto, el centro histórico de la ciudad de Puerto Varas (mixto) presenta una revitalización más significativa (60\%), considerando los cuatro componentes del sistema patrimonial, lo que dista de ser cercano al óptimo teórico de 100.

De acuerdo con la metodología aplicada, los factores de éxito del barrio que ocupa el primer lugar relativo radican en la evolución de los componentes vivienda, espacio público y capital social (pero no desarrollo económico patrimonial), los cuales muestran tendencias valorizantes, lo que ocurre de manera similar en el barrio de Puerto Varas (mixto) y Huemul (residencial). En Yungay, barrio mixto icono del patrimonio en Santiago, las grandes fortalezas han sido las otras dimensiones de capital socia y de economía patrimonial, muy diferentes de la regla promedio, pero desafortunadamente acompañadas de indicadores de espacio público y vivienda rezagados. En Viña del Mar (mixto) la mejora de vivienda ha sido el principal vector de revitalización, puesto que se trata de un barrio acomodado y turístico que incluye palacios con centros culturales de buen estándar, a pesar de lo cual su capital social patrimonial es muy bajo porque no tuvo la activación ocurrida en Yungay.

Al otro extremo del ranking, todos los componentes de sistema patrimonial muestran estancamiento y riesgo de grave deterioro. En el caso de Guayacán destaca la carencia de desarrollo económico patrimonial y el deterioro del espacio público y el hábitat residencial; en el caso de Mapocho, por su parte, el mayor deterioro viene dado por la degradación del espacio público. Los barrios La Matriz y El Almendral, ambos de la ciudad

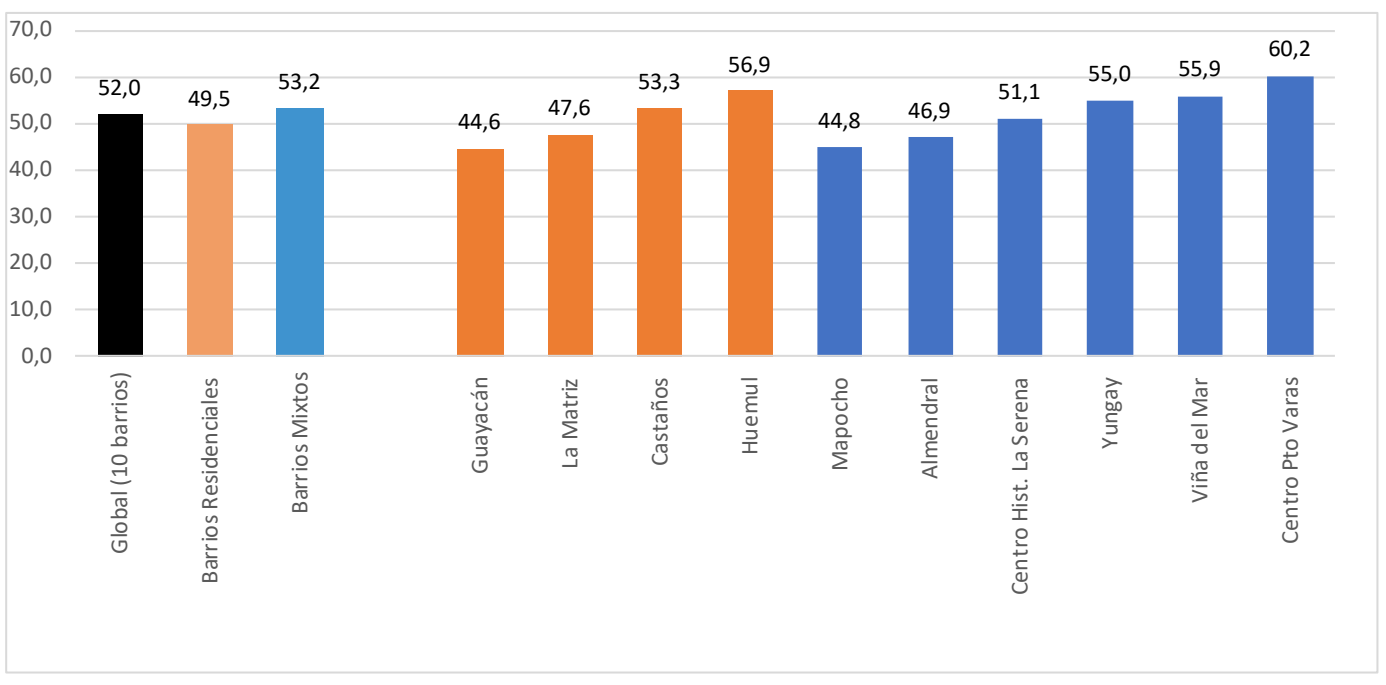

Figura 3: Resultados IEBP en 10 barrios, valor para el conjunto de barrios y comparativo de barrios de tipo mixto (barras azules) y residencial (barras naranjas)

Fuente: Elaboración propia con base en metodología IEBP (encuesta de barrios patrimoniales, observación y datos censales) 
de Valparaíso, reportan una evolución económica patrimonial rescatable, favorecida por el auge de la imagen de patrimonio de la humanidad que promovió la declaratoria UNESCO, pero que no logra contrarrestar el elevado deterioro en sus componentes del estado de la vivienda y espacio público, respectivamente tensionadas por el sub-arriendo precario y el auge de comercio informal callejero, que incluso expulsa locales tradicionales.

Observados los componentes del sistema patrimonia (Figura 4), por separado, el IEBP muestra que, en los 10 barrios estudiados, los componentes de vivienda y economía patrimonial logran, ambos, un 57\% de potencial de revitalización. Se trata de un nivel moderado, pero desmiente la idea extendida según la cual los barrios tenderían al deterioro por efecto de la protección patrimonial, a la vez que muestra un involucramiento en algunos de casos de inversionistas en el mejoramiento de inmuebles. Por su parte, el componente entorno urbano solo mejora un $51 \%$ de su potencial. El eslabón más débil es el capital social vinculado al patrimonio (45\% de mejora), con la excepción de los casos de Yungay y Puerto Varas, mencionados previamente, ambos de tipo mixto.
En lo referente al componente vivienda, que parece un gran vacío de políticas, la encuesta de barrios patrimoniales aplicada reporta que, tras las iniciativas de protección patrimonial de los barrios, un 37\% percibe un mejoramiento del estado de conservación de las viviendas (de la calle o pasaje inmediato de los encuestados), mientras que un $26 \%$ reporta deterioro. Un 50\% percibe mejoras de los locales comerciales, especialmente en La Serena. Un 60\% de los encuestados declara haber realizado mejoras en sus viviendas después de las declaratorias como barrios patrimoniales, especialmente destacables en Puerto Varas, Mapocho, Almendral. y Viña del Mar, que se trata de barrios mixtos, la mayoría de gran tamaño y visibilidad urbana

Como correlato a la percepción del estado de conservación de inmuebles patrimoniales que se recoge a través de la encuesta, los datos recabados mediante observación directa, muestran que, en promedio, $58,4 \%$ de las manzanas tiene algún inmueble de interés patrimonial (Figura 5). Respecto a su conservación, el IEBP muestra que la percepción ciudadana denota una tendencia al estancamiento en su mantención y conservación, siendo mejor la percepción de conservación de monumentos e iglesias que la de otro tipo de inmuebles patrimoniales.

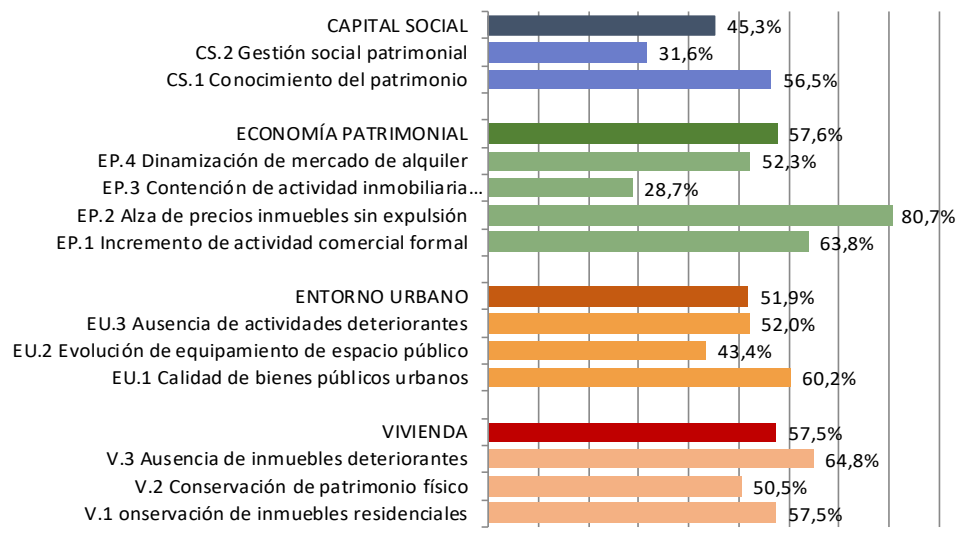

Figura 4: Resultados IEBP en 10 barrios, comparación por subíndices

Fuente: Elaboración propia con base en metodología IEBP (encuesta de barrios patrimoniales, observación y datos censales)

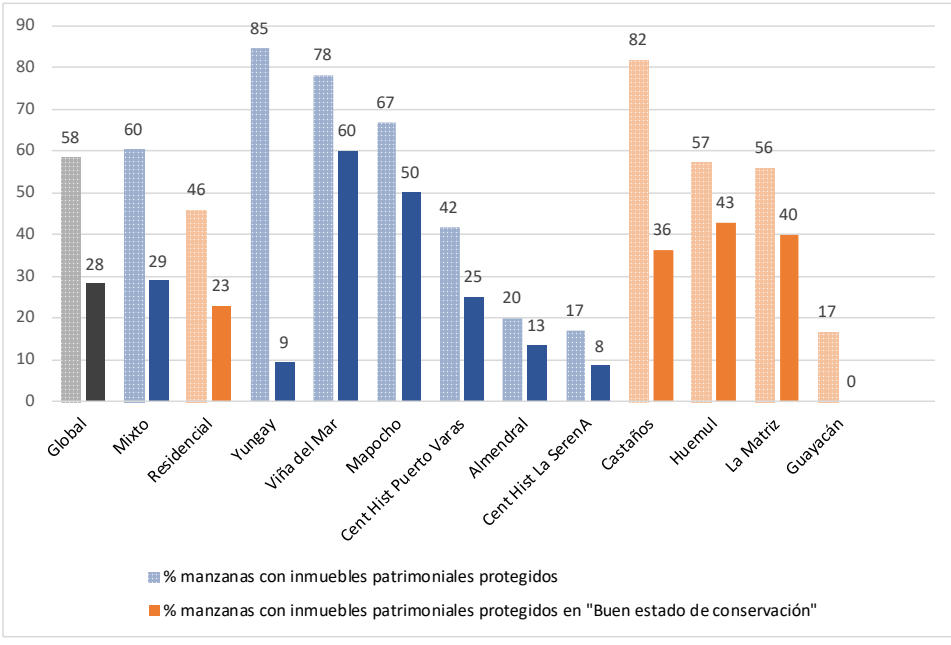

Figura 5: Porcentaje de manzanas con inmuebles patrimoniales protegidos (barras achuradas-sombreadas) y Porcentaje de manzanas en buen estado de conservación (barras sólidas) en barrios mixtos (barras azules) y residenciales (barras naranjas)

Fuente: Elaboración propia a partir de entrevistas y observación 
En cuanto al patrón de localización de las iniciativas de protección de inmuebles en las zonas típicas y/o de conservación histórica, el estudio reporta una gran heterogeneidad interna, desde acciones dispersas a intervenciones aglomeradas. Este aspecto fue profundizado por las cartografías, las cuales muestran que el número y porcentaje de manzanas donde se localizan inmuebles sometidos a alguna protección patrimonial, constituyen una clave respecto de la factibilidad de gestionar una revitalización. En efecto, las peores mantenciones de inmuebles y monumentos se detectan en El Almendral y en Mapocho, donde ese estado de conservación se correlaciona con una mayor superficie y un patrón de localización disperso; en ambos casos se trata de barrios mixtos de gran impacto en sus áreas urbanas, donde es evidente que ha faltado selectividad y focalización por manzanas o cuadrantes más estratégicos que orienten la puesta en valor y no la fragmentación de la norma.

Respecto al entorno urbano (Figura 7), la encuesta muestra diferencias vinculadas al tipo de espacio público que ha sido mejorado con posterioridad a las protecciones patrimoniales. Así, las plazas y parques son mejor evaluados en su mantención después de las declaratorias (48\%), seguidos por las luminarias y juegos infantiles (42\% de percepción de buen estado en cada caso). En contraste, los equipamientos públicos que reciben evolución negativa son los paraderos de transporte público y el mobiliario urbano, situación muy sensible en barrios mixtos de alta movilidad de población flotante.

La percepción de actividades o usos que deterioran e invaden del espacio público es preocupante en la mayoría de barrios. Los aspectos que más consenso arrojan en cuanto a su carácter negativo son la presencia de rayados murales, la vagancia de perros y el consumo y venta de drogas, percibidos en un $75 \%$ de las viviendas encuestadas. Ello tiene un efecto de deterioro en el IEBP de los barrios Yungay, centro histórico de La Serena, El Almendral, La Matriz y Mapocho. Todos se tratan de barrios mixtos. Por su parte, el comercio informa callejero, sin alcanzar los niveles de insatisfacción previos, igual se declara en un $44 \%$ de los consultados como un elemento de deterioro presente, lo que genera mayor consenso en Yungay, Almendral, Matriz y Mapocho (entre $60 \%$ y $90 \%$ de los encuestados). Estos son barrios mixtos en 3 de los 4 casos.

Respecto al componente economía patrimonial (Figura 8) para un $66 \%$ de los encuestados la actividad inmobiliaria de renovación urbana en altura aumentó después de la protección, percepción que alcanza cifras muy elevadas entre los vecinos de Viña del Mar, Yungay, Los Castaños y Mapocho (3 de 4 son mixtos). En segundo término, $50 \%$ de los encuestados declara un incremento de restaurantes y cafeterías de buen estándar (percepción que aumenta en La Serena, Viña del Mar y Puerto Varas) esto es, todos barrios mixtos. También incremento en barrios mixtos de puesta en venta o arriendo de casas antiguas (en especial en La Serena, Viña del Mar, Yungay, Mapocho y Almendral), junto con la expansión de locales comerciales en general (Almendral, Yungay y Mapocho). Por otra parte, un tercio de las viviendas ha recibido ofertas de compra por empresas inmobiliarias, cifra que es bastante mayor en barrios de tipo mixto (36\%) y en los barrios de la Región Metropolitana (43\%), comparados con el barrio patrimonial de Puerto Varas, donde solo un $20 \%$ ha recibido ofertas.

El IEBP arroja algunos indicios respecto de gentrificación, capturando la percepción de aumento de residentes de mayor nivel socioeconómico. Los datos de encuesta indican que solo un $12 \%$ de los vecinos percibe un aumento de habitantes de mayor nivel socioeconómico, cifra que crece al $25 \%$ en Puerto Varas.

Por último, en relación con el componente capita social patrimonial (Figura 9), la encuesta muestra que el conocimiento de la comunidad respecto de los diferentes tipos de inmuebles de valor cultural presentes en su territorio es bajo $y$, salvo excepciones, como Yungay, aparece como un activo dormido. Entre un 33\% y $50 \%$ de vecinos declara conocer y estar involucrado en e patrimonio, destacando específicamente el conocimiento de la arquitectura patrimonial en El Almendral y Viña de Mar, ambos mixtos. La historia del barrio es el elemento más conocido en barrios pequeños residenciales, como Los Castaños. Lo menos conocido y entendido es el tipo de protección patrimonial del barrio e inmuebles y lo que ello implica.

Finalmente, la participación en acciones de mejora de patrimonio solo llega al 36\%, pero crece en Puerto Varas, Yungay y Huemul (2 mixtos y 1 residencial pero adyacente a un barrio mixto), y cae bajo el $9 \%$, e incluso 0\%, en Guayacán y Castaños (ambos residenciales). En todo caso, se trata de resultados más positivos que los captados por la Encuesta de Participación Cultural (Consejo Nacional de la Cultura y las Artes [CNCA], 2017) que reporta un $16 \%$ de visitas a los espacios que contienen una herencia cultural arquitectónica, por debajo incluso del interés por la riqueza natural y de monumentos de carácter religioso (29\% y $20 \%$, respectivamente).

\section{Conclusiones}

El IEBP es una herramienta eficiente que permite obtener un balance estratégico sobre cambios ocurridos a escala de barrios protegidos (agregando procesos vecinales y prediales), lo cual arroja antecedentes de manera integral para efectos de una mejor gestión del patrimonio local, sectorial y regional. En particular, aporta un marco de indicadores de un campo de política que ha carecido de información estandarizada, al menos en el contexto chileno y donde los datos reconocen la importancia del tipo de barrio mixto versus residencial en orden a efecto diferencial por territorios de los distintos factores o componentes, situación invisibilizada por sesgos arquitectónicos y monumentalistas de la disciplina y consiguientes vacíos de políticas

Comparando los diferentes componentes de este instrumento, se advierte que la imagen de deterioro generalizado que impera respecto de los barrios patrimoniales es inexacta. El componente entorno urbano muestra una cierta tendencia al estancamiento, lo cual representa un enorme desafío para las políticas públicas de regeneración y mejoramiento urbano en cuanto a focalizar en áreas patrimoniales, en especial mixtas, expuestas al desgaste de grandes flujos de población flotante. El eslabón más débil es 

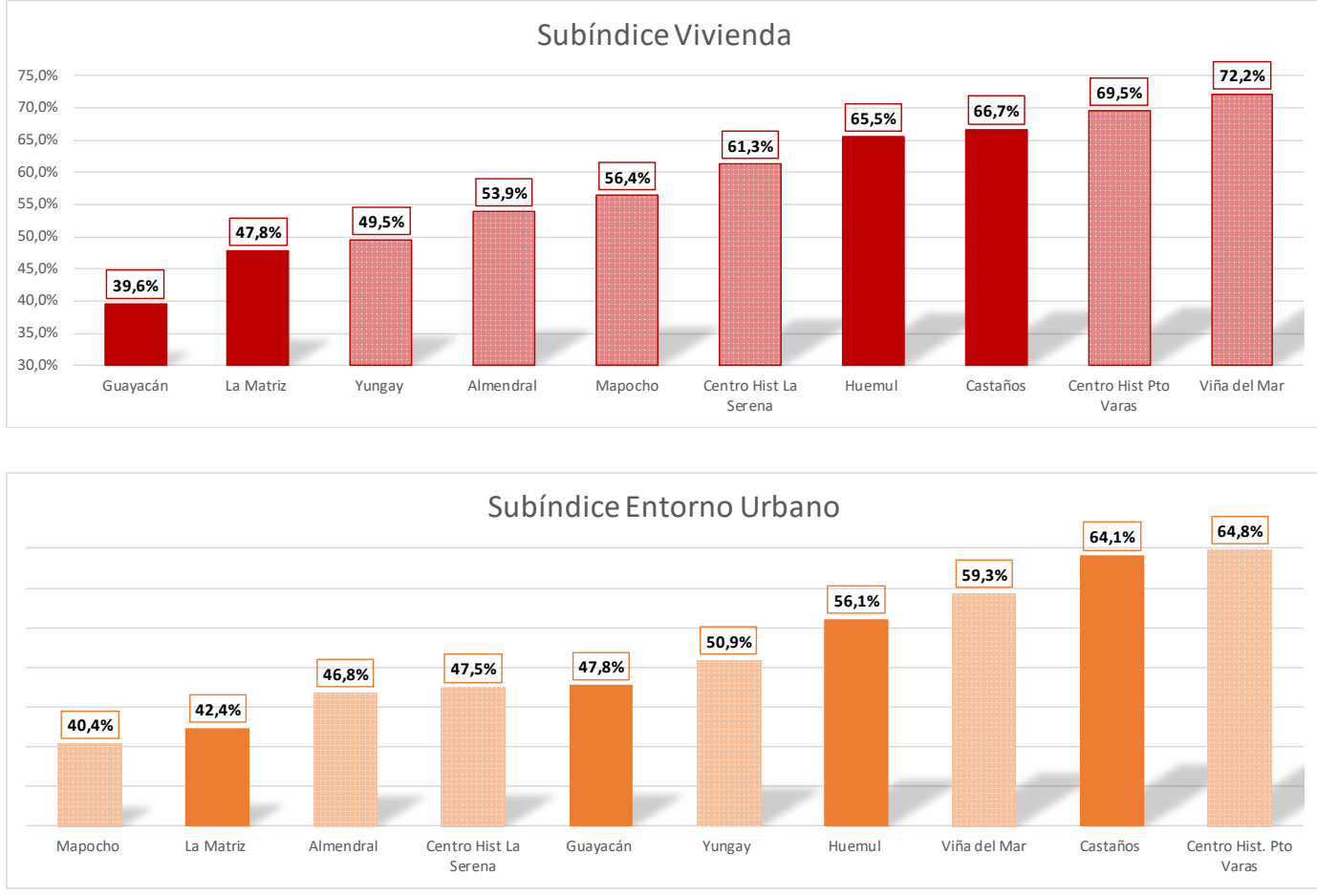

Subíndice Economía Patrimonial

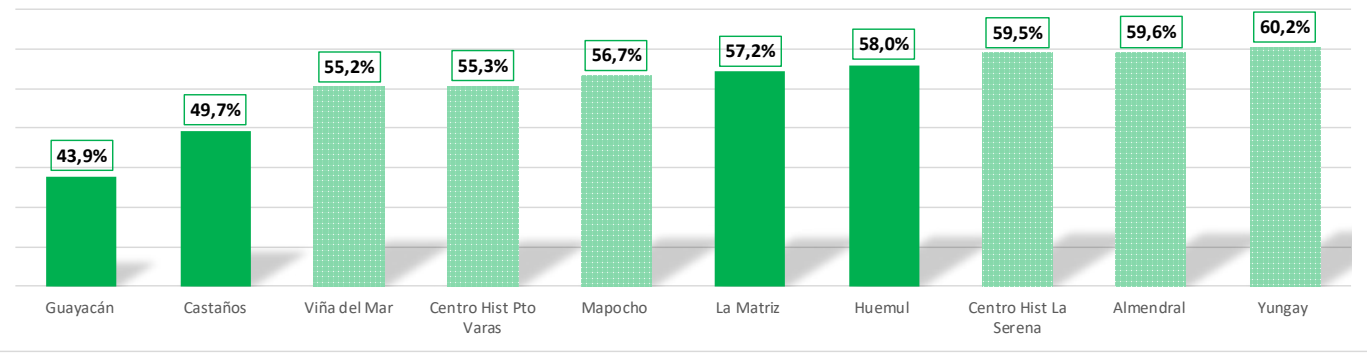

Subíndice Capital social y Gestión social del patrimonio

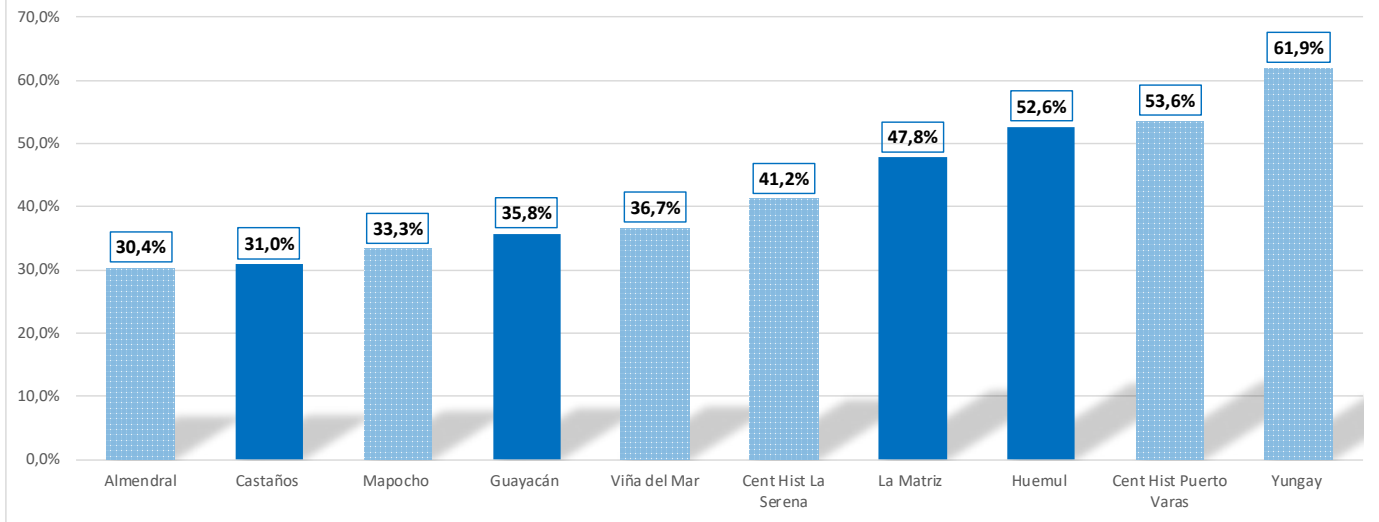

Figuras 6-7-8-9: Resultados subíndices de IEBP en los barrios mixtos (barra achurada-sombreada) y residenciales observados (barra sólida)

Fuente: Elaboración propia con base en metodología IEBP (encuesta de barrios patrimoniales, observación y datos censales) 
el componente capital social vecinal, vinculado a la identidad y asociatividad comunitarias, el cual, como tendencia general, muestra un cierto rezago, pese a que buena parte de las protecciones patrimoniales surgen de iniciativas ciudadanas (Yungay, barrio mixto cultural, es la excepción y cuenta además con un mayor desarrollo de componente de economía patrimonial). Ello, sin duda, da cuenta de una falta de instrumentos que fortalezcan y den soporte a aquellas organizaciones vecinales cuya finalidad sea la conservación del patrimonio barrial y la identidad cultural vinculada a un tipo de desarrollo local.

El manejo del crecimiento urbano y habitacional de zonas patrimoniales aparece como el mayor desafío para la gestión de zonas patrimoniales insertas en áreas metropolitanas. Durante el período 2002-2017, la población en estas zonas aumentó de menos de 10 mil personas a 48 mil, contraviniendo la imagen extendida de tendencia al despoblamiento. Sin embargo, el estancamiento del parque de viviendas es notable. Como total, se cuantifican 18 mil hogares en solo $3 \mathrm{mi}$ viviendas, lo que da un déficit habitacional cuantitativo, interno a barrios protegidos, superior a 15 mil unidades. Los casos más extremos son Yungay, Almendral, Mapocho y centro histórico de La Serena, todos mixtos. Esta situación puede explicarse por el hecho de que e crecimiento de población se realizó por la densificación del parque existente, sin localización de viviendas económicas, a la par del creciente uso y demanda de localización comercial y externalidades varias del alto flujo de transeúntes.

Por último, en la arista de planificación urbana, la aglomeración o dispersión de los inmuebles protegidos por manzana, junto al tamaño de la superficie protegida, determinan ciertos efectos que deben ser analizados por las políticas de revitalización de barrios patrimoniales. Los casos de Valparaíso y Puerto Varas, en extremos distintos del índice de evolución, son muy pedagógicos a este respecto. A partir de ellos, se infiere la conveniencia de una política de protección más selectiva, y concentrada por manzanas, como visión más realista del desarrollo de estrategias pro-recuperación, y que sea complementada por políticas de integración a la trama urbana mediante la habilitación de espacios de circulación estratégicos. Dicho de otro modo, se advierte la posible inconveniencia de proteger un gran número de inmuebles dispersos y aislados en muchas manzanas de zonas muy extensas, sin una estrategia previa de mantención de inmuebles y sin una visión estratégica de los espacios públicos estructurales como soporte de economía y capital social patrimonial.

Cómo citar este artículo/How to cite this article: Arriagada-Luco, C. y Jeri-Salgado, T. (2022). Revitalización de barrios patrimoniales en áreas metropolitanas: propuestas de monitoreo y gestión integrada. Estoa. Revista de la Facultad de Arquitectura y Urbanismo de la Universidad de Cuenca, 11 (21),103-116. https://doi.org/10.18537/est.v011. n021.a09

\section{Referencias bibliográficas}

Arriagada, C. (2013). Nuevo urbanismo, globalización urbana y aplicación del concepto no lugar. AUS [Arquitectura / Urbanismo / Sustentabilidad], (14), 11-14. https://doi.org/10.4206/aus.2013.n14-03

Arriagada, C. (2018). Aportes para un modelo de regeneración integral de barrios patrimoniales en Chile, tendencias del entorno urbano y políticas públicas. En XXII Congreso ARQUISUR La dimensión Pública de la Arquitectura: Libro de ponencias (pp. 885-889). Rosario, 26-28 septiembre, 2018. Universidad Nacional de Rosario, AGP Ediciones. http://rephip.unr.edu.ar/xmlui/ handle/2133/13849

Arriagada, C. y Berg, L. (2019). Impacto de los instrumentos de protección patrimonial sobre la dinámica de barrios metropolitanos mayores y emergentes: hacia un modelo de monitoreo y revitalización [Informe de resultados no publicado].

Banco Interamericano de Desarrollo (BID) (2019). Las Industrias culturales y creativas en la Revitalización Urbana. BID

Banco Interamericano de Desarrollo (BID). (2015). Chile. Programa de Revitalización de Barrios e Infraestructura Patrimonial Emblemática (CH-L1084). [Perfil de Proyecto]. BID. https://ewsdata.rightsindevelopment. org/files/documents/84/IADB-CH-L1084.pdf

Banco Interamericano de Desarrollo (BID). (s.f.). CH-L1084 Revitalización de Barrios e Infraestructura Patrimonia Emblemática: Plan de monitoreo y evaluación. BID.

Bassols, M., Donoso, R., Massollo, A. y Méndez, A (Comps.). (1988). Antología de sociología urbana. Universidad Nacional Autónoma de México.

Blalock, H. (1986). Estadística Social. Fondo de Cultura Económica. http://www.terras.edu.ar/ biblioteca/15/15MIS_Blalock_Unidad_3\%5B1\%5D.doc. pdf

Bruquetas Callejo, M., Moreno Fuentes, F. J. y Walliser Martínez, A. (2005). La regeneración de barrios desfavorecidos. Documento de trabajo 67. Fundación Alternativas. https://www.fundacionalternativas.org/ laboratorio/documentos/documentos-de-trabajo/laregeneracion-de-barrios-desfavorecidos

Cámara Chilena de la Construcción $(\mathrm{CCHH})$ y Pontificia Universidad Católica de Chile (PUC). (2019). Índice de Calidad de Vid Urbana 2019. CCHC, IEUT-UC. https:// estudiosurbanos.uc.cl/en/documento/indice-de-calidadde-vida-urbano-2019-icvu/

Carrión, F. (Ed.). (2001). Centros Históricos de América Latina y el Caribe. FLACSO-Sede Ecuador. https:// biblio.flacsoandes.edu.ec/shared/biblio_view. php?bibid $=11257 \&$ tab=opac

Communities and Local Government. (2009). Local Index of Child Well-Being. Summary Report. Communities and 
Local Government Publications. https://www.york.ac.uk/ inst/spru/research/pdf/locallndexCWB.pdf

Consejo Nacional de Desarrollo Urbano (CNDU). (2014). Política Nacional de Desarrollo Urbano. Ciudades sustentables y calidad de vida. Ministerio de Vivienda y Urbanismo, Chile / Programa de Naciones Unidas para el Desarrollo. https://cndu.gob.cl/wp-content/ uploads/2014/10/L4-Politica-Nacional-Urbana.pdf

Consejo Nacional de Desarrollo Urbano (CNDU). (2017). Sistema de indicadores y estándares de calidad de vida y desarrollo urbano. Informe CNDU. Consejo Nacional de Desarrollo Urbano / Programa de Naciones Unidas para el Desarrollo. https://cndu.gob.cl/wpcontent/uploads/2018/03/1.-PROPUESTA-SISTEMA-DEINDICADORES-Y-EST\%C3\%81NDARES-DE-DESARROLLOURBANO.pdf

Consejo Nacional de Desarrollo Urbano (CNDU). (2018). Propuestas para un modelo integral de conservación del desarrollo urbano. Consejo Nacional de Desarrollo Urbano / Programa de Naciones Unidas para e Desarrollo. https://cndu.gob.cl/download/propuestas para_un_modelo_integral_de_conservacion_del_ patrimonio_urbano/

Consejo Nacional de la Cultura y las Artes (CNCA) (2017). Encuesta Nacional de Participación Cultura 2017. CNCA. https://www.cultura.gob.cl/wp-content/ uploads/2018/03/enpc_2017.pdf

European Commission. (2013). Urban Audit. Perception Survey in 79 European cities. Quality of life in cities. Publications Office of the European Union. https:// ec.europa.eu/regional_policy/sources/docgener/ studies/pdf/urban/survey2013_en.pdf

García Canclini, N. (1989). Culturas Hibridas. Estrategias para entrar y salir de la modernidad. Grijalbo.

Hall, P. (1996). Ciudades del mañana: historia del urbanismo del siglo XX. Ediciones del Serbal.

Hernández, J. (2011) Los caminos del patrimonio. Rutas turísticas e itinerarios culturales. Pasos. Revista de Turismo y Patrimonio Cultural, 9 (2), 225-236

Hernández Sampieri, R., Fernández, C. y Baptista, P. (2006) Metodología de la Investigación (4ạ ed.). Mac Graw-Hill / Interamericana.

Instituto Nacional de Estadísticas (INE). (2017). Resultados Censo 2017. INE. http://resultados.censo2017.cl/

MERCER. (2019). Quality of living city ranking. 2019 city ranking. https://mobilityexchange.mercer.com/insights/ quality-of-living-rankings

Programa de Naciones Unidas para el Desarrollo (PNUD). (2019). Informe sobre desarrollo humano 2019: Más allá del ingreso, más allá de los promedios, más allá del presente: Desigualdades del desarrollo humano en el siglo XXI. PNUD. http://hdr.undp.org/sites/default/files/ hdr_2019_es.pdf
Resonance Consultancy. (2020). World Best Cities 2020 A Ranking of Global Place Equity. Best Cities Division, Resonance Consultancy. https://www.pwc.dk/da/ publikationer/2020/pwc-worlds-best-cities-report-2020. pdf 